\title{
THE FUNDING SCHEME "IMPACT INNOVATION" - THE IDEA BEHIND AND THE RESULTS OF AN ASSESSMENT
}

PHILIPP AIGINGER-EVANGELISTI, BARBARA GLINSNER AND DOROTHEA STURN DOI: $10.22163 /$ fteval.2020.466

\section{WHY "IMPACT INNOVATION"?}

I

n February 2017 the Austrian Research Promotion Agency (FFG) started with a first call of the funding scheme "Impact Innovation".

pursued three objectives:

- Broadening the innovation base through a broader understanding of innovation to include problem-based, non-technological innovation and innovation outside of traditional R\&Dareas including social innovations, business model innovations and service innovation in diverse fields such as education, journalism and social inclusion;

- Broadening access to FFG funding for actors who have not been addressed by FFG instruments so far (e.g. start-ups, social enterprises, associations);

- More successful innovation projects through an early involvement of relevant actors, a structured and methodically guided approach along an innovation process, orientation towards problem solving and learning experiences on the problem in the course of project implementation.

Against the background of these objectives, the pilot programme aimed at innovation projects in their very early stages of the develop- ment process, as Figure 1 illustrates. In contrast to traditional RqD-funding instruments an in-depth problem analysis, the ideation process and the idea selection formed an integral part of the projects to be funded. Therefore, the projects' evaluation focused on the innovation process rather than on the research and/or market potential as it is usually done both by FFG and most European Innovation Agencies.

\section{MOTIVATION FOR THE NEW PROGRAMME "IMPACT INNOVATION"}

For the last decades Innovation Agencies used to fund innovations which were R\&D- and technology-based. However, facing the societal and economic challenges and the likely transformational processes, efforts by research promotion agencies to support non-technological innovation could be noticed throughout Europe (e.g. the scheme "Feelings" from Tekes [now Business Finland] or the "Business Innovation Initiative" from Enterprise Ireland). In the FFG the first steps were taken with the introduction of the "service innovation initiative" and the "innovation voucher" scheme. But although both funding schemes were important

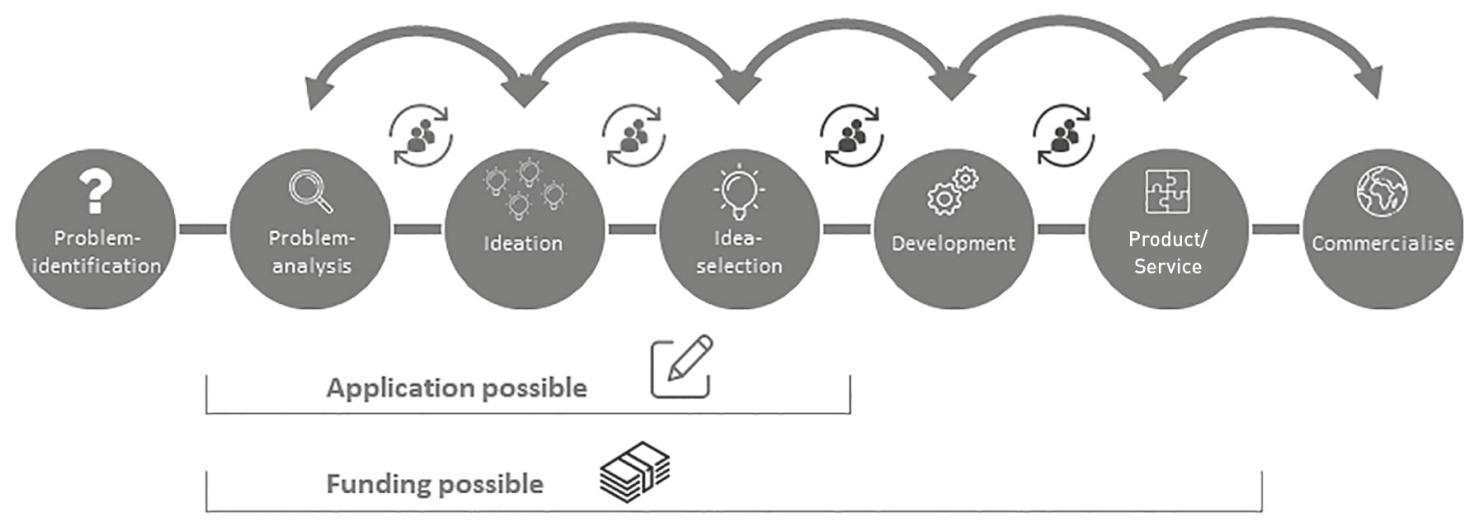

Figure 1: „Impact Innovation“: Interactive Development of innovative Ideas and Solutions,

Source: FFG (https://www.ffg.at/programm/impactinnovation), own translation 
milestones towards a new understanding of innovation by including nontechnical innovations consciously, they were overall still rooted in the same narrow understanding of innovation as R\&D driven.

So far, innovation was first and foremost conceptualised as the outcome of R\&D activities that followed a linear process and resulted in new technological solutions (see Figure 2). This also becomes apparent when looking into the state aid rules for R\&D aid, whose underlying rationale is a narrow concept of the market failure theorem. ${ }^{1}$ The major argument in this context is the public good argument of R\&D, which stipulates that new knowledge can be appropriated by competitors, thus hindering innovators from claiming $100 \%$ of the benefits ${ }^{2}$ from their innovation while bearing all the risks connected with it. This assumed disproportion would lead to diverging private and social profits and non-optimal investments. Correcting market failure ${ }^{3}$ has traditionally been the core argument for the funding activities of Innovation Agencies.

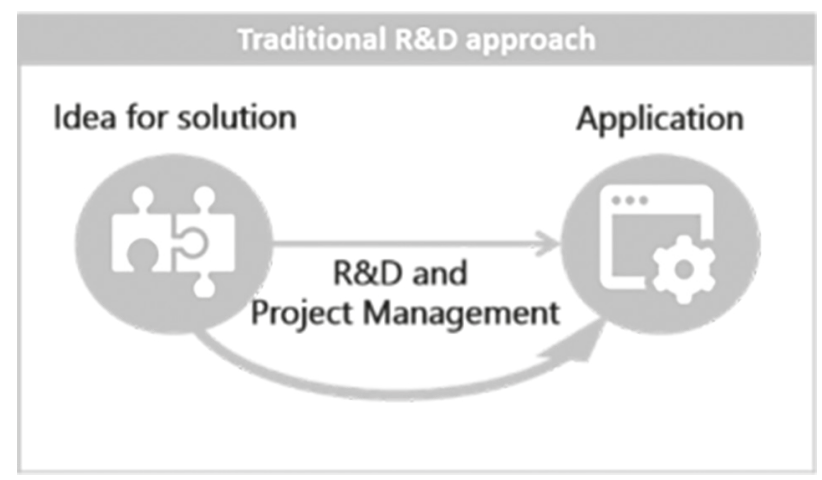

Figure 2: Traditional approach - Use of R\&D to achieve the project goals Source: FFG, internal use

However, this traditional focus of the Austrian Research Promotion Agency on R\&D-based technological innovation failed to attract new forms of innovations, particularly non R\&D based innovation. This shortcoming was also pointed out by some of FFG's network partners (e.g. chamber of commerce) and communities (e.g. start-ups) and became apparent when the FFG dealt with new target groups such as lean startups of the service economy. As a consequence, FFG started to rethink its approach by discussing with other Innovation Agencies of the TAFTIE ${ }^{4}$ network and by forming mainly internal working groups. Although the goal was to think openly and allow for new ideas, the persistence of the traditional approach based on the above mentioned narrow concept of market failure became obvious. As with the well-established FFG-Programmes, discussions about the sufficient level of innovation and risks of the projects were dominating the debate. Thus, updating the traditional concept of innovation to include non-technological innovation as well as to enlarge the target group of FFG programmes to attract new, nontraditional innovators (such as social innovators) required a change in perspective as well as inspiration from outside the traditional innovation policy's ecosystem.

FFG therefore assigned a small innovation consulting company "WhatAVenture" to get a clearer picture of innovation processes, modern innovation methodologies and the needs of non-technological innovators with regard to support structures and funding instruments. By including "unusual suspects" (for the FFG, such as social or cultural nonprofit organisations) and Lead Users that the FFG considered innovative, but who didn't perform R\&D (such as designers, social entrepreneurs) it became evident that the available funding instruments were not flexible enough to allow for iteration, learning and stakeholder involvement.

\section{WHAT ABOUT THE MARKET FAILURE, WHERE ARE THE RISKS?}

The market failure argument on information asymmetries, risk aversion and uncertainty can be mitigated through a more inclusive development process. In a paper about non-technical $R \& D$ the authors conclude that uncertainties are rooted in the user acceptance of new

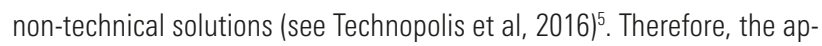
proach to start with user's problems and involving them in the iterative development process as illustrated in Figure 1, seems very appropriate to overcome uncertainties. SMEs do not follow this path (enough) without public interventions, because of the constraints in resources (incl. finance, time, staff, networks) and a lack of qualification. This market failure argument, emphasizing the role of uncertainties, differs from the previous mentioned public good argument and substantiates the approach of insisting on a thorough innovation process.

The importance of the innovation process required a shift in assessing project proposals as well: Instead of assessing the level of innovation, technical risks to overcome (otherwise no real research is needed) and the market potential of the solution, it might be more important to assess the set-up of the innovation process and the future potential, if everything works as planned. So to say: instead of assessing the solution, start with the problem and how you want to proceed to solve it. The assumption is, that if there is a problem without sufficient solutions, any solution to this problem will have an impact. It seems more uncertain to assess market potential in two to three years (or even longer) than assessing the effects of problems now. The hypothesis here is "The bigger the effects of a problem, the bigger the impact of the solution ".

\footnotetext{
1 There is a long list of literature that evidences that appropriation is not an easy exercise, because of the cumulative, tacit nature of technical knowledge (e.g. Pavitt, 1984; 1987, 1999; Nelson \& Winter 1982).

2 The idea of research as a public good goes back to Nelson (1959), Arrow (1962), and Buchanan (1968). For a taxonomy of various patterns of technical change see Pavitt (1984).

3 The market failure rationale includes also other than the 'public good of RqD' argument such as the information asymmetries and risk aversion argument, the divergence between private and social (investment) time preferences argument, the indivisibleness and technical large-scale risks argument etc.

$4 \quad$ The European Network of Innovation Agencies, see https://www.taftie.org

5 The Oslo Manual 2018 (OECD 2018) as well as the European Innovation Scoreboard (European Commission 2019) also introduced innovations which are not R\&D based.
} 


\section{PILOTING THE APPROACH}

With this new approach to support also non-technical innovations, the notion of innovation became more diverse. However, there were still a lot of unknowns and uncertainties on how to design a programme for this purpose: How do these new types of projects look like? From which industries will the proposals come? What kind of organisations will apply? Is it the right approach at all? Since these are quite severe questions, FFG decided to use a design approach to develop and test each step. Partly with established network partners, partly with lead users and partly with newly established networks (social innovation community) small elements were tested (criteria, application, communication) and iterated before starting a funding call. Although over the course of 1.5 years FFG already learned a lot about new target groups, a lot of uncertainty about demand and understanding of the needs remained. This was why FFG decided to carry out a small pilot call. The mobilisation of the applicants was facilitated by the newly established networks, the Lead Users and multipliers that the FFG had identified.

The following table gives an overview of the key figures of the pilot call.

\begin{tabular}{|l|l|}
\hline Project volume: & up to $150,000 €$ \\
\hline Funding quota: & $50 \%$, up to $75,000 €$ \\
\hline Duration: & up to 12 months \\
\hline Number of submissions: & 104 \\
\hline Accepted projects: & $16(=15 \%)$ \\
\hline $\begin{array}{l}\text { Applicants with previous } \\
\text { FFG experience: }\end{array}$ & $37(=36 \%)$ \\
\hline Target group: & $\begin{array}{l}\text { SMEs including start-ups and } \\
\text { enterprises in the course of } \\
\text { formation, corporations and } \\
\text { partnerships, associations, } \\
\text { NPOs, individuals }\end{array}$ \\
\hline
\end{tabular}

Table 1: Key figures of the pilot call of "Impact Innovation" Source: own elaboration

\section{ASSESSING THE PILOT PROGRAMME}

\section{THE FFG ASSESSED THE PILOT PROGRAMME IN TWO STEPS:}

First, the FFG assigned BlueLab with assessing the service design of the pilot call directly after the funding decisions to learn about the applicants' understanding of the call, their motivations for applying (simplicity and problem focus) and to better understand their innovation processes. Regarding the communication of the pilot programme it turned out that the reference model of an innovation process (see Figure 2) was simple but very effective to establish a common understanding, everyone involved could refer to. This quick evaluation enabled quick changes for the following call 2018.

Second, the Centre for Social Innovation (ZSI) was assigned with assessing whether the pilot call has met the programme's objectives. ZSI's approach comprised the following methods:

- First, a descriptive analysis of the applying organisations on the basis of the FFG database was compiled.

- Second, building on this analysis semi-structured interviews with successful and rejected applicants were carried out to assess the funding instrument at project-level. The aim was to understand how funded projects designed and implemented the innovation process, how they involved stakeholders and deployed innovation methods as demanded by the programme.

- Third, ZSI conducted a focus group with experts in the fields of innovation (policy), including start-ups, social entrepreneurship and crowd-funding experts as representatives of a broader innovation eco-system understanding to assess the impact of the new funding instrument at programme level and in the Austrian innovation system.

\section{ATTRACTING NEW INNOVATORS}

In the course of the Pilot call, 104 organisations or individuals submitted their proposals to the FFG of which only 16 were chosen for funding. The objective of attracting new applicants was well achieved. 65 percent of them were first-time applicants while only 17 applicants had already submitted more than 10 proposals during the last 20 years. Interestingly, experienced applicants were not more successful in obtaining funding than those who had no prior experience in submitting proposals to the FFG. "Impact Innovation" is only open to small firms and organisations; it was nevertheless surprising that the majority of organisations applying were micro-enterprises or sole entrepreneurs, only three had more than 50 employees. The thematic focus of the submitted proposals was categorised according to the $\mathbf{S D G} \mathbf{s}^{6}$ by the FFG. In general, the submitted proposals could be attributed to eleven out of the 17 SDGs pointing to the heterogeneity of the problems the proposals wanted to tackle. Most submissions could be attributed to SDG 9 "Industry, Innovation and Infrastructure", which is the traditional focus of FFG. However, only two of them were funded. Although it is difficult to draw conclusions regarding the approval rate per SDG given the low number of cases, it can be said that a third of the projects, which contributed in total to SDG 4 "Quality Education", SDG 8 "Decent Work and Economic Growth" as well as SDG 15 "Life on Land" were chosen for funding. The funding instrument managed to attract a new group of applicants, that (i) mostly had no or little experience in applying to FFG, (ii) were SMEs (mostly micro-enterprises) and (iii) aimed at finding solutions for a variety of problems that are usually not within the scope of traditional funding instruments of FFG (see Table 2). 


\begin{tabular}{|c|c|c|}
\hline Project Focus & Applicant & Region \\
\hline Social Inclusion of Elderly via Virtual Reality & SME (Start-Up) & Upper Austria \\
\hline GEARing up Innovation in Diagnostics for Antibiotic Resistance & SME (Start-Up) & Vienna \\
\hline Development of a Bayesian planning HR and ePlanning Tool in Health Services & SME (Start-Up) & Upper Austria \\
\hline Virtual Reality as an HR Development Tool & SME (Start-Up) & Tyrol \\
\hline $\begin{array}{l}\text { Open Innovation Process Development for Scaling and Multiplying } \\
\text { Impact - Impactful Preschool- and Parents' programmes }\end{array}$ & SME (non-profit) & Vienna \\
\hline $\begin{array}{l}\text {-Service Tool to Simplify Shopping and Delivery for Chinese } \\
\text { Tourists in Europe (who mostly shop for their relatives and } \\
\text { often don't' get to experience the city they are visiting) }\end{array}$ & Sole Entrepreneur & Vienna \\
\hline $\begin{array}{l}\text { New Tool for Levelling out the Under-construction of Terraces to } \\
\text { simplify and drastically shorten the installation process }\end{array}$ & SME & Upper Austria \\
\hline $\begin{array}{l}\text { Development of a community-based Learning Approach for } \\
\text { Journalists to tackle new challenges in (traditional) media }\end{array}$ & Association & Vienna \\
\hline $\begin{array}{l}\text { Biomimicry Thinking Design Process as an innovation method } \\
\text { for the craftsmen of the "Werkraum Bregenzerwald" }\end{array}$ & Association & Vorarlberg \\
\hline Development of an Online-Platform to configurate and market funeral services & SME (Start-Up) & Vienna \\
\hline Development of an Al Tool to assess the "easy to read" criteria of texts & SME (Social Enterprise) & Styria \\
\hline $\begin{array}{l}\text { Automatic Translation of Package Leaflets of } \\
\text { Pharmaceutical Products in Sign Language }\end{array}$ & SME (Social Enteprise) & Vienna \\
\hline $\begin{array}{l}\text { Integrative Property Management that takes social } \\
\text { and economic aspects into account }\end{array}$ & SME (Social Enterprise) & Styria \\
\hline Development of Innovative Support Services for Social Entrepreneurs in Rural Areas & Intermediary Organisation & Vienna \\
\hline $\begin{array}{l}\text { Development of a tool to make use of local expert knowledge } \\
\text { to assess natural hazards for traffic infrastructures }\end{array}$ & SME (Start-Up) & Tyrol \\
\hline Development of an Orientation Guide for Feminine Hygiene Products & SME (Social Enterprise) & Vienna \\
\hline
\end{tabular}

Table 2: "Overview of the funded projects of the pilot call of "Impact Innovation" Source: own elaboration

The interviews with applicants revealed that the programme was attractive to them for three reasons:

- First, in comparison to other funding schemes, the call was open to many forms of organisations and therefore constituted one of very few possibilities for associations or sole entrepreneurs to have their innovation activities funded.

- Second, as pointed out above, the broader definition of innovation enabled non-technological innovations such as service or process innovations, which are supported by only few other funding instruments in Austria.

- Third, as intended by the programme design, the interviewed applicants appreciated that the focus of "Impact Innovation" lies on the innovation process itself rather than on a pre-defined result. This focus gave applicants the freedom and the resources to understand the complex issues they were facing, test their central assumptions, do prototyping and adapt their solutions if necessary, whereas traditional funding instruments often demand to follow the plan and solutions laid out in the application form.

One of the interviewees stated:

"Impact Innovation is a new idea, a new aspect which is treated only rarely. I think It is cool that the FFG is going to fund such projects." (own translation) 


\section{INNOVATION THROUGH NEW INNOVATIVE METHODS AND STAKEHOLDER ENGAGEMENT}

In line with the focus on the innovation process, the programme made it compulsory for funded projects to apply innovation methods such as design thinking, hackathons or innovation workshops. Hence, all of the funded projects applied these methods, albeit to a different extent. On the one hand, those organisations or projects that were wellestablished and directed the funds towards developing a new activity, service or product in addition to their core business designed their innovation process quite carefully. They "innovated" in a specific setting, with dedicated time, resources and used creative, innovative or scientific methods. On the other hand, those organisations that were in their start-up phase handled the innovation process more flexible. Innovation methods as well as constant testing and adaption are an integral part of their tacit knowledge and hence their daily activities, but often not reflected. Furthermore, the funded projects all engaged their most important stakeholder (groups), mostly to obtain feedback and test central assumptions. However, none of the funded project fully integrated stakeholders into the innovation process. In conclusion, the assessment recommended a better explanation and trainings of innovation and co-creation methods for the applicants to ensure that they are well-understood and do fertilize the innovation process.

\section{OUTCOMES AND IMPACTS AT PROJECT LEVEL}

The pilot call of "Impact Innovation" can be regarded as successful since every funded project produced valuable outcomes. Many projects could test their central assumptions by engaging their key stakeholders. Moreover, the innovation process helped to improve the "solution-fit" of the developed process, service or product. Those projects that aimed at developing an app or a web-platform managed to create prototypes which are well advanced, but not yet market-ready. Interestingly, the engagement of stakeholders and the innovative solutions contributed to the improvement of existing products and services as well.

As described above, one of the programme objectives was to broaden the understanding of innovation to include non-technological innovation and innovation outside of traditional R\&D-areas. The assessment identified three different kinds of innovations; two of them being non-technological:

- The first group of innovations can be labelled as innovative education/training and service concepts. Mostly by making knowledge more accessible through adapting it to the needs of their target groups those projects contributed to the empowerment of vulnerable groups, increased transparency for customers and encouraged actors in finding innovative ways of dealing with societal challenges themselves.

- The second group consists of projects developing digital services like platforms or apps to link stakeholders, improve services and the accessibility of information for their users.

- The third and smallest groups were technological innovations.
It is important to underline that the largest innovation potential lied in the combination of the three forms of innovation. With the exception of two projects, all developed innovative concepts and services either had a digital or a technological aspect. However, compared to traditional R\&D the technological innovation here was minor and would have not been funded by traditional instruments. In the context of "Impact innovation" technological innovations constituted a means in delivering services to a (partly marginalized) target group.

Beyond those outcomes the funded projects also created valuable impacts. By engaging with stakeholders, the funded projects created vital links among those stakeholders and therefore contributed to a stronger integration of the field they are active in. Taking on the role as an innovation leader in their field, they could also increase their own visibility and reputation. In two cases the funding scheme "Impact Innovation" was even a vital factor in the constitution of the funded organisation. Furthermore, the interviews revealed that the applicants would not have been capable (mostly due to lack of resources) to find innovative solutions without obtaining funding by this programme. Therefore, it can be concluded that the programme filled a gap in the funding ecosystem.

Although all of the funded projects achieved great results, they are now faced with the challenge of further developing their solutions to make them market-ready. For well-established for-profit enterprises the further development of their innovations is a strategic decision of whether to invest own resources or not. Start-ups and social entrepreneurs, however, often lack the financial and time resources to carry their innovation process forward. Therefore, they need to find adequate follow-up funding opportunities. Given the scarcity of funding opportunities for social enterprises the lack of follow-up funding is threatening the innovation to be fully realised.

\section{PROGRAMME'S AND ECOSYSTEM'S LEVEL}

The "Impact Innovation" programme itself is an innovative initiative which fills a gap in the funding landscape. In the current innovation ecosystem, there is nearly no comparable funding scheme that works with such a broad understanding of innovation, which explicitly includes nontechnological innovations, and starts at this early stage of the problem identification:

- It allows more time and resources to be invested in the innovation and development process. This enables stakeholders to become better involved and results in a targeted use of innovation methods.

- It enables the promotion of innovative activities for beneficiaries for whom no adequate funding programme exists in the field. Through the programme, some social enterprises have been able to implement innovation activities.

- With its broader concept of innovation, the programme occupies an almost unique position in Austria's funding eco-system with a great potential for innovative projects.

Although the pilot programme has a perceptible impact on the innovation ecosystem, its explicit inclusion of social and educational enterprises also raised a number of issues that were discussed, particularly within the focus group. Consideration was for instance given to dividing the programme into two lines of intervention. A first line of intervention 
could be aimed at social enterprises that provide innovative solutions for services in the public interest and do not operate in a market or quasimarkets, while a second line of intervention could promote market-oriented innovation with societal impacts.

Whatever the outcome of a decision on this issue will be, "Impact Innovation" is currently filling the gap in the creation of early-stage innovations, which is a unique selling point in the portfolio of innovation support schemes.

\section{CONCLUSIONS AND RECOMMENDATIONS}

Despite the consistently positive results that have been shown, the programme presents a number of challenges which require further reflection. These refer to the programme's key objectives of addressing new types of innovation and new target groups. The assessment therefore ends with the following recommendations:

- Welcome new applicants more explicitly and develop specific formats for advising them

- Rethink a matching of FFG's funding with crowd-funding

- Simplify formal requirements as far as possible

- Systematically give feedback to the applicants and projects

- Initiate exchange among projects

- "Mainstream" "Impact Innovation": Integrate some of the programme's characteristics into other funding schemes.

- Develop ways and methods to assess the projects' impacts

- Communicate the programme and projects more clearly

- Address regional multipliers in all Austrian provinces

\section{IMPLEMENTATION OF RECOMMENDATIONS}

Some changes in the call 2019 directly refer to these recommendations, especially the ones on establishing networks between funded projects and the provision of tailor-made support for new applicants. In addition, the communication with regional multipliers outside Vienna was improved. In 2020, a pilot on Social Crowdfunding (matching public funding with crowd funding) will be launched. There is still some progress to be made to mainstream the "Impact Innovation" approach, but also to communicate the importance of thorough innovation processes - even beyond R\&D - to applicants or potential applicants.

\section{REFERENCES}

Arrow, K. J. (1962): Economic Welfare and the Allocation of Resources for Invention. In Universities-National Bureau Committee for Economic Research, Committee on Economic Growth of the Social Science Research Council (ed): The Rate and Direction of Inventive Activity: Economic and Social Factors, Princeton University Press

Buchanan, J.M. (1968): Demand and Supply of Public Goods, Chicago: Rand McNally \& Company.
European Commission (2019): European Innovation Scoreboard https://ec.europa.eu/growth/industry/innovation/facts-figures/scoreboards_en

OECD (2018): Oslo Manual. Guidelines for Collecting, Reporting and Using Data on Innovation, 4th Edition, Paris.

http://www.oecd.org/science/oslo-manual-2018-9789264304604-en.htm

Nelson, R. R. (1959): The simple economics of basic scientific research. Journal of Political Economy, LXVII (3), June, 297-306.

Nelson, R.R. \& Winter S.G. (1982): An Evolutionary Theory of Economic Change. Cambridge, Massachusetts: The Belknap Press of Harvard University Press.

Pavitt, K. (1984): Sectoral patterns of technical change: towards a taxonomy and a theory. Research Policy 13, 343-373.

Pavitt, K. (1987): Technological accumulation, diversification and organisation in UK companies, 1945-1983. DRC discussion paper, Science Policy Research Unit, University of Sussex.

Pavitt, K. (1999): Technology, Management and Systems of Innovation. Edward Elgar Publishing

Technopolis et al. (2016): Ökonomische und verwaltungstechnische Grundlagen einer möglichen öffentlichen Förderung von nichttechnischen Innovationen

https://www.bmwi.de/Redaktion/DE/Publikationen/Studien/studie-zunichttechnischen-innovationen.pdf?_blob=publicationFile $\& v=2$

United Nations (2019): The Sustainable Development Goals Report 2019 https://unstats.un.org/sdgs/report/2019/The-Sustainable-DevelopmentGoals-Report-2019.pdf

\section{AUTHORS}

\section{PHILIPP AIGINGER-EVANGELISTI}

FFG - Austrian Research Promotion Agency

Sensengasse 1, 1090 Wien

E: Philipp.Aiginger@ffg.at

\section{BARBARA GLINSNER}

ZSI - Centre for Social Innovation

Linke Wienzeile 246, 1150 Vienna

E: glinsner@zsi.at

\section{DOROTHEA STURN}

ZSI - Centre for Social Innovation

Linke Wienzeile 246, 1150 Vienna

E: sturn@zsi.at

\section{KEYWORDS:}

non-technological innovation, innovation processes, social innovators, stakeholders' involvement 